University of Nebraska - Lincoln

DigitalCommons@University of Nebraska - Lincoln

Roman L. Hruska U.S. Meat Animal Research

U.S. Department of Agriculture: Agricultural Center

Research Service, Lincoln, Nebraska

1997

\title{
Calculation Of Fractal Dimension From Cattle Thermoregulatory Responses
}

\author{
R. L. KORTHALS \\ USDA-ARS \\ Y. R. CHEN \\ USDA-ARS
}

G. L. HAHN

USDA-ARS, hahn@email.marc.usda.gov

R. A. EIGENBERG

USDA-ARS

Follow this and additional works at: https://digitalcommons.unl.edu/hruskareports

KORTHALS, R. L.; CHEN, Y. R.; HAHN, G. L.; and EIGENBERG, R. A., "Calculation Of Fractal Dimension From Cattle Thermoregulatory Responses" (1997). Roman L. Hruska U.S. Meat Animal Research Center. 204. https://digitalcommons.unl.edu/hruskareports/204

This Article is brought to you for free and open access by the U.S. Department of Agriculture: Agricultural Research Service, Lincoln, Nebraska at DigitalCommons@University of Nebraska - Lincoln. It has been accepted for inclusion in Roman L. Hruska U.S. Meat Animal Research Center by an authorized administrator of DigitalCommons@University of Nebraska - Lincoln. 


\title{
CALCULATION OF FRACTAL DIMENSION FROM CATTLE THERMOREGULATORY RESPONSES
}

\author{
R. L. KORTHALS,' Y. R. CHEN, ${ }^{2}$ G. L. HAHN' ${ }^{\prime}$ and R. A. EIGENBERG' \\ 'Roman L. Hruska U.S. Meat Animal Research Center (MARC), USDA-Agricultural Research \\ Service, Clay Center, NE 68933-0166, U.S.A. and '2.S. Beltsville Agricultural Research Center \\ (BARC), USDA-Agricultural Research Service, Instrumentation and Sensing Laboratory, Beltsville, \\ MD 20705, U.S.A.
}

(Received 13 December 1996; accepted in revised form 11 June 1997)

\begin{abstract}
Fractal dimension analyses have previously been shown to objectively classify thermoregulatory responses of cattle to non-stressing and stressing thermal environments. This report presents a geometric method for calculating fractal dimensions $(D)$ from time-series datasets of tympanic temperatures, and evaluates the effects of sampling intervals, recording system resolution and noise, and length of sample datasets on the calculated $D$-value. From these analyses, recommendations were developed for minimum temperature data resolution $\left(0.16^{\circ} \mathrm{C}\right.$ ), sampling interval (3 to $15 \mathrm{~min}$ ), and data set length (integer multiples of $24-\mathrm{h}$ periods). To reduce the impact of 'noise' in the recording system to less than $5 \%$ change in the D-value, the number of errors times the magnitude of the errors $\left({ }^{\circ} \mathrm{C}\right)$ should be limited to 0.64 when substituting for missing or questionable data. The fractal dimension computed using the prescribed technique with data collected according to the recommended criteria allows use of all collected data, without requiring removal of underlying deterministic functions or filtering of the data. The method is robust and provides objective differentiation of thermal stress levels in cattle, thereby serving as a basis for environmental evaluation and management. Published by Elsevier Science Ltd
\end{abstract}

Key Word Index: chaos; stress; environment; tympanic; temperature; thermoregulation; animals

\section{INTRODUCTION}

Fractal dimension has been used to classify observed characteristics of many nonlinear physical and biological systems (Mandelbrot, 1983). Fractals are defined as a class of mathematical functions that are invariant over a wide range of scales (Mandelbrot, 1983). Fractal dimension analysis provides a means to evaluate and quantify the level of stochastic variability of a system. Fractal geometry has been suggested as a new basis for understanding physiological systems, particularly in the context of homeodynamics which recognizes that physiological systems have some level of intrinsic variability (West and Deering, 1995). Hahn et al. (1992) computed fractal dimensions from the tympanic temperatures of growing cattle to objectively classify thermoregulatory responses to non-stressing and stressing thermal environments. A subsequent study used fractals to compare housing effects on neonatal calves, and to assess the effects of acclimation to potentially stressing cool conditions (Macauley et al., 1995). The change in fractal dimension when exposed to stressors can be used to quantitatively assess threshold stress levels and an animal's ability to cope with the stressor (Hahn et al., 1992). Ultimately, fractal dimensions computed from thermoregulatory responses provide animal caretakers another means of evaluating their management of animal stress.

Sections 2 and 3 provide further background on the problem and describe the technique used for fractal dimension calculation. Some of the requirements and caveats of fractal dimension calculation are discussed, using example results obtained from cattle tympanic temperatures that show the potential value of fractal dimension as a tool for quantifying stress in animals.

\section{BACKGROUND}

Animals are living, dynamic organisms possessing several interacting subsystems (von Bertalanffy, 1968, p. 44). As a result, the response of an animal to a stressor is complex, and an overall index of stress remains elusive. Endocrine (cf. Carsia and Weber, 1988) and similar measures (Smidt, 1983) are limited by the invasiveness of the procedures and the difficulty involved in taking such measures from unconfined animals. Animal energetics, such as feed 
intake and heat production, also have been used for evaluating stress (cf. National Research Council, 1981, 1987; Nienaber and Hahn, 1991). Feed intake, although very important to production, provides only a gross measure of stress. Heat production provides more information than feed intake, but it requires sophisticated equipment and analysis. Improvements in portable data logging capabilities have made field measurements of body temperatures and thermoregulation using tympanic temperatures practical (Hahn, 1989; Hahn et al., 1990a; Eigenberg et al., 1995; Korthals et al., 1992, 1995). Tympanic temperatures are useful because they are a non-invasive procedure that correlates well to hypothalamic thermoregulatory body temperatures (Baker et al., 1972; Benzinger, 1959, 1964; Findlay and Ingram, 1961; Scott et al., 1970).

The interactions of animal subsystems can be considered chaotic, in that the actual state of the overall system cannot be estimated with sufficient accuracy to make long-term forecasts of responses to given input conditions. Several procedures can be used to model chaotic systems (Adachi and Kotani, 1994; Ellner et al., 1992), but unmeasured, random perturbations to chaotic systems will eventually make predictions of their state incorrect. Earlier efforts using Data Dependent Systems (DDS) and Green`s function analysis to evaluate thermoregulatory responses to thermal environments were helpful in detecting treatment differences and illustrating system dynamics, but questions remained about the robustness of DDS procedure for modeling data with deterministic periodicity and trends (Parkhurst and Hahn, 1987, 1989: Hahn et al., 1987). These questions led to nonlinear dynamic evaluations of tympanic temperature datasets. Fractal dimension analysis provided an effective means to quantify the changes in tympanic temperatures that were visually apparent.

\section{DEVELOPMENT OF FRACTAL ANALYSIS METHODOLOGY}

One non-linear dynamics analysis technique using fractal dimensions is fractional Brownian motion (fBm) (Otto-Pietgen and Saupe, 1988; Pentland, 1984; Stepp, 1995). Segments of fractal Brownian functions are statistically similar to each other, and are statistically invariant over wide transformations of scale. Mathematically, this self-similarity is described such that, for each $t$ and $\Delta t$ (Otto-Pietgen and Saupe, 1988):

$$
\text { Probability }\left\{\frac{T(t+\Delta t)-T(t)}{|\Delta t|^{H}}<k\right\}=F(k)(1)
$$

where $T(t)$ is $\mathrm{fBm}, t$ is time, $F(k)$ is a distribution function, and $H$ is the scaling parameter.

For $\mathrm{fBm}$ with a topological dimension of 1 , it can be shown (Voss, 1988) that:

$$
D=2-H,
$$

where $D$ is the fractal dimension. The fractal dimension of a fractal line, $D$, is always higher than its topological dimension one (a straight line) and lower than two (a plane). Physically, a low $D$ (near one) represents domination of a long term variability or a trend, while a large $D$ (near two) represents a response dominated by short term variations. It is usually easier to model simple systems with a low $D$ than complex systems characterized by a high $D$.

From the definition of $\mathrm{fBm}$, and assuming that animal tympanic temperature $T(t)$ is $\mathrm{fBm}$. it can be shown from equation (1) that, for all:

$$
\begin{gathered}
\left|t_{2} \quad t_{1}\right| \cdot \\
E\left[\left|T\left(t_{2}\right)-T\left(t_{1}\right)\right|\right]=a\left|t_{2}-t_{1}\right|^{H}
\end{gathered}
$$

where $E$ is the expectation and $a$ is a proportionality constant.

For discrete time series data, sampling at every point from 1 to $n$ on a fixed interval, a MEAN, which is the sampling mean of $n$ absolute differences of two adjacent points, can be computed:

$$
M E A N=n^{-1} \sum_{i=1}^{n}\left|T\left(t_{t+1}\right)-T\left(t_{i}\right)\right|
$$

We further define a MEAN of a separation interval $N$ to be

$$
\operatorname{MEAN}(N)=n^{-1} \sum_{i=1}^{n}\left|T\left(t_{i+N}\right)-T\left(t_{i}\right)\right|
$$

where $N=2,3,4,5, \ldots, n$. In equation (5) the absolute difference is not between two adjacent points, but between two points separated by $N$ intervals.

We also define a function $R(N)$ to be:

$$
R(N)=\frac{M E A N}{M E A N(N)}
$$

$R(N)$ can be computed based on equations (4) and (5).

Assuming that the animal tympanic temperature is stationary, from equations (3) and (4), the MEAN can be expressed as:

$$
E A N=a\left|t_{i}-t_{i-1}\right|^{H}
$$

because $T(t)$ is $\mathrm{fBm}$. Similarly, equation (5) can be expressed as:

$$
E A N(N)=b\left|t_{i}-t_{-N}\right|^{H},
$$


where $b$ is a proportionality constant. Since, for equal intervals,

$$
\left|t_{1}-t_{i-N}\right|=N\left|t_{i}-t_{i-1}\right|,
$$

then equation (8) can be expressed by:

$$
\operatorname{EAN}(N)=b N^{H}\left|t_{1}-t_{i-1}\right|^{H} .
$$

From equations (7),(10), we have:

$$
R(N)=c N^{-H}
$$

or

$$
=c N^{D-2}(N)
$$

where $N=2,3,4,5, \ldots, n$, and $c$ is a constant of proportionality.

Equations (11) and (12) indicate that the relationship between $\log (R(N))$ and $\log (N)$ is linear for $\mathrm{fBm}$, and:

$$
H=1-S
$$

and

$$
D=1+S
$$

where $S$ is the slope of the plot of $\log (R(N))$ against $\log (N)$, as illustrated by Fig. 2 of Hahn et al. (1992). Equation (11) was used for determination of the fractal dimension from the animal tympanic temperatures. It should be noted that variations in the circadian temperature rhythm were not filtered out; to do so removes essential information for computing the fractal dimension.

\section{DATASETS}

Three datasets were used to develop and test fractal dimension analysis for cattle. The first dataset was obtained from 6 growing, ad-libitum-fed steers (Bos taurus). These data were collected using portable dataloggers with thermistor sensors recording tympanic temperatures at 320 -s intervals with a resolution of $0.1^{\circ} \mathrm{C}$. This dataset was originally used to develop fractal dimension analysis of animal tympanic temperatures and to test fractal dimensions for evaluating stress (Hahn et al., 1990b).

The second dataset was obtained in 1990 from a similar set of 6 growing, ad-libitum-fed steers (Bos taurus). The 1990 data were obtained using a central datalogger with thermocouple sensors recording at 15-s intervals. This dataset was used to further evaluate the use of fractal dimension to recognize and quantify the distinct tympanic temperature patterns for an animal exposed to non-stressing and stressing controlled-environment temperatures. These data were also used to determine appropriate sampling frequencies for use in fractal dimension analysis of cattle tympanic temperatures (Hahn et al., 1992).

A third dataset was used to evaluate cattle (Bos taurus) tympanic temperature datasets for the effects of resolution, Gaussian random noise, and bad or missing data points on the calculation of fractal dimensions. This dataset consisted of 32 daily records of tympanic temperatures from 8 growing, adlibitum-fed steers with a range of fractal dimensions from 1.2 to 1.8 . These data were recorded at $128-\mathrm{s}$ intervals using a commercial datalogger with a measurement resolution of $0.04^{\circ} \mathrm{C}$. Criteria for selecting data for use were completeness of the file and absence of anomalous readings.

\section{DATA ISSUES}

\section{Sampling interval}

Fractal dimensions were computed from the 1990 dataset of individual animal tympanic temperatures sampled at $10-\mathrm{m}$ intervals for multiple days during the later stages of exposure to non-stressing and stressing environments (Table 1). Although all animals had similar fractal dimensions under thermoneutral conditions of $10 \pm 7^{\circ} \mathrm{C}$ cyclic conditions, the rate at which the animal's fractal dimension decreased with increasing thermal stress varied $(P<0.001$, Hahn et al., 1992). That analysis also compared sub-samples of the 1990 tympanic temperature dataset at various multiples of the 15-s sampling rate to determine the effect of sampling

Table 1. Fractal dimensions $(D)$ of the tympanic temperature of individual cattle during late stages of exposure to non-stressing and stressing environments (1990 data recorded at 15-s intervals and sampled at 10-min intervals; $D$-values are averages of 7 days \pm SD) (Hahn et al., 1992)

\begin{tabular}{lcccccc}
\hline $\begin{array}{l}\text { Environmental } \\
\text { temperature }\end{array}$ & \multicolumn{5}{c}{ Steer } \\
\cline { 2 - 7 }$\left({ }^{\circ} \mathrm{C}\right)$ & 1 & 2 & 3 & 4 & 5 & 6 \\
\hline $10 \pm 7$ & $1.733( \pm 0.132)$ & $1.733( \pm 0.109)$ & $1.755( \pm 0.093)$ & $1.815( \pm 0.151)$ & $1.813( \pm 0.086)$ & $1.781( \pm 0.050)$ \\
$30 \pm 7$ & $1.344( \pm 0.090)$ & $1.628( \pm 0.133)$ & - & - & $1.647( \pm 0.110)$ & $1.587( \pm 0.091)$ \\
$32 \pm 7$ & $1.196( \pm 0.054)$ & $1.557( \pm 0.134)$ & $1.377( \pm 0.102)$ & $1.358( \pm 0.124)$ & - & - \\
$34 \pm 7$ & - & - & $1.235( \pm 0.107)$ & $1.368( \pm 0.071)$ & $1.395( \pm 0.079)$ & $1.418( \pm 0.085)$ \\
\hline
\end{tabular}


Steer 4 (90956)

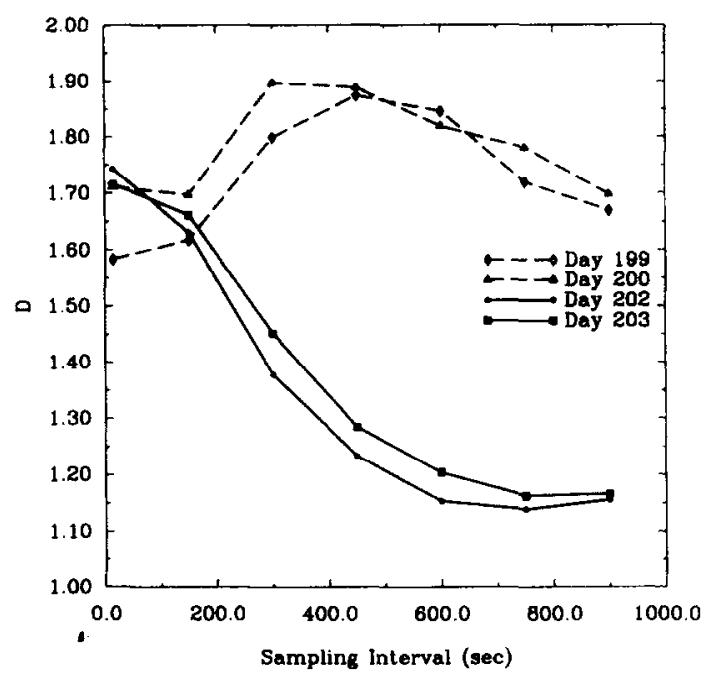

Fig. 1. Fractal dimensions of tympanic temperature determined for an example animal at various sampling rates under thermoneutral $\left(---, 10 \pm 7^{\circ} \mathrm{C}\right.$, day 199 and 200$)$ and heat stress (-, $34 \pm 7^{\circ} \mathrm{C}$, day 202 and 203) conditions (Hahn et al., 1992).

interval on the fractal dimension. Environmental treatments are distinguishable at sampling intervals of $180 \mathrm{~s}(3 \mathrm{~min})$ or greater, as illustrated in Fig. 1, with the differentiation becoming more definitive as sample intervals increase to about $600-750 \mathrm{~s}$ (10-12.5 min). At a sampling interval of $150 \mathrm{~s}$ ( $2.5 \mathrm{~min}$ ) or less, fractal dimensions are essentially the same for all environmental treatments (Table 2) and are somewhat unstable. Other data subsets confirm the need for a minimum sampling interval of greater than $120 \mathrm{~s}$ for fractal computations.

Lower fractal dimensions indicate that only a few mechanisms dominate the thermoregulatory response of stressed animals. In contrast, the animals under thermoneutral conditions utilize a range of mechanisms to cope with their environment. This fits the mathematical expectations that higher fractal dimensions result from more complex systems and lower fractal dimensions from simpler systems.

\section{Partial days}

Tympanic data for a partial day do not give the same fractal dimension as the full day's data, because they are not truly fractal in that they fail Mandelbrot's (1983) stated assumption that fractal dimension is invariant with the size of the dataset. The regular cycles in tympanic temperature during a day yield different fractal dimensions when comparing datasets covering part of a day with datasets taken over other portions of the day or the full day. As an example, fractal dimensions of $1.66,1.37$, and 1.31 were computed for the two one-half day segments, and a full day's record from a dataset sampled at 256-s intervals. It is possible that an animal when sleeping will exercise fewer thermoregulatory behaviors and have a different fractal than when that same animal is active. If that is true, then thermoregulation may be a multi-fractal response. While this does not imply that fractal dimensions taken for a specific portion of a day cannot be used as a measure of stress, it does demonstrate that fractal dimensions computed from data for partial days should only be compared with analyses of data taken during the same time period each day. Whether cattle thermoregulation is a multi-fractal and if fractal dimension analysis of a partial day's data can be used to characterize stress are topics for further research. In contrast to data for partial days, calculating fractal dimensions on multiple days' data yields similar results to averaging the fractal dimension calculated for each of the individual days. This is as expected from the calculation of $R(N)$ (equation (6)) used to derive the fractal dimensions.

\section{Resolution}

To evaluate the effects of resolution on fractal dimension, modified datasets were created from the third dataset. Lower resolution datasets were derived from the original $0.04^{\circ} \mathrm{C}$ resolution data (Fig. 2a) Intermediate resolution steps $\left(0.04^{\circ} \mathrm{C}\right)$ were eliminated to simulate a loss of resolution to $0.08^{\circ} \mathrm{C}$. Data points that were between multiples of $0.08^{\circ} \mathrm{C}$ were

Table 2. Fractal dimensions of the tympanic temperatures of steers in non-stressing and stressing environmental temperatures-from 1990 data recorded at 15-s intervals (Hahn et al., 1992)

\begin{tabular}{lcc}
\hline & \multicolumn{2}{c}{ Computed fractal dimension \pm SD } \\
\cline { 2 - 3 } $\begin{array}{l}\text { Environmental } \\
\text { temperature }\left({ }^{\circ} \mathrm{C}\right)\end{array}$ & $\begin{array}{c}\text { Based on all 15-s interval data } \\
\text { points in daily record }\end{array}$ & $\begin{array}{c}\text { Based on sampling 15-s dataset every } \\
\text { 20th point (300-s) intervals) }\end{array}$ \\
\hline $10 \pm 7$ & $1.728 \pm 0.068(24)^{*}$ & $1.782 \pm 0.079(20)$ \\
$30 \pm 7$ & $1.694 \pm 0.036(16)$ & $1.686 \pm 0.119(14)$ \\
$32 \pm 7$ & $1.687 \pm 0.126(16)$ & $1.512 \pm 0.156(16)$ \\
$34 \pm 7$ & $1.716 \pm 0.070(15)$ & $1.436 \pm 0.356(13)$
\end{tabular}

*Parenthetical numbers are the steer-days of record used from the 6 steers in the experiment. 


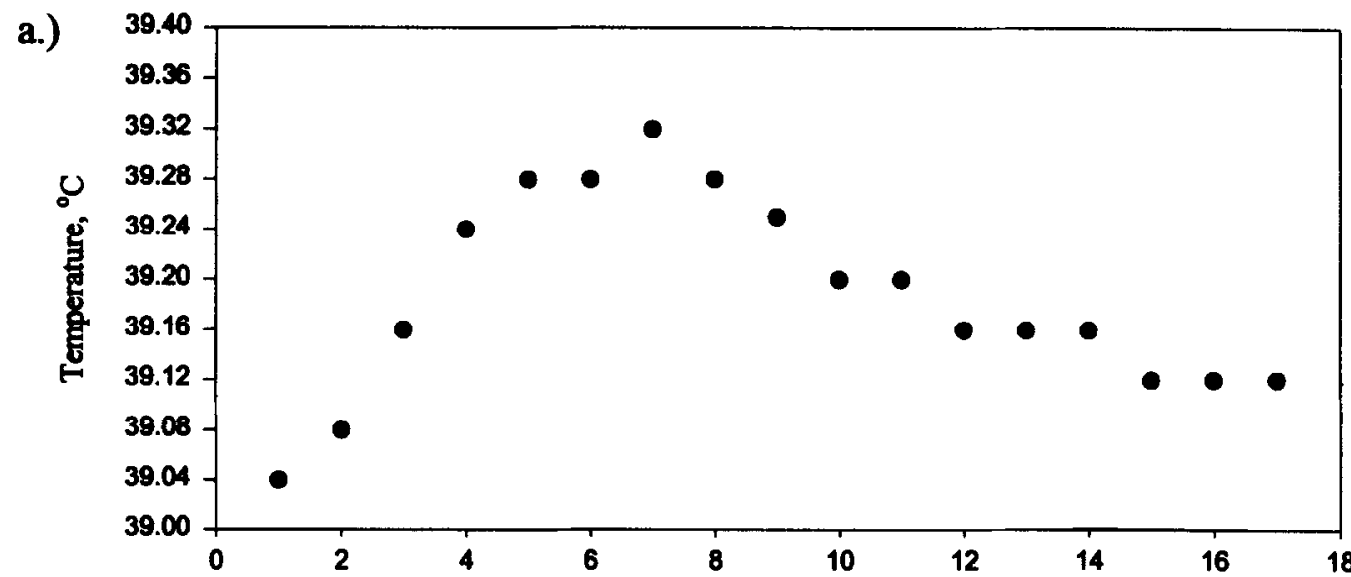

b.)

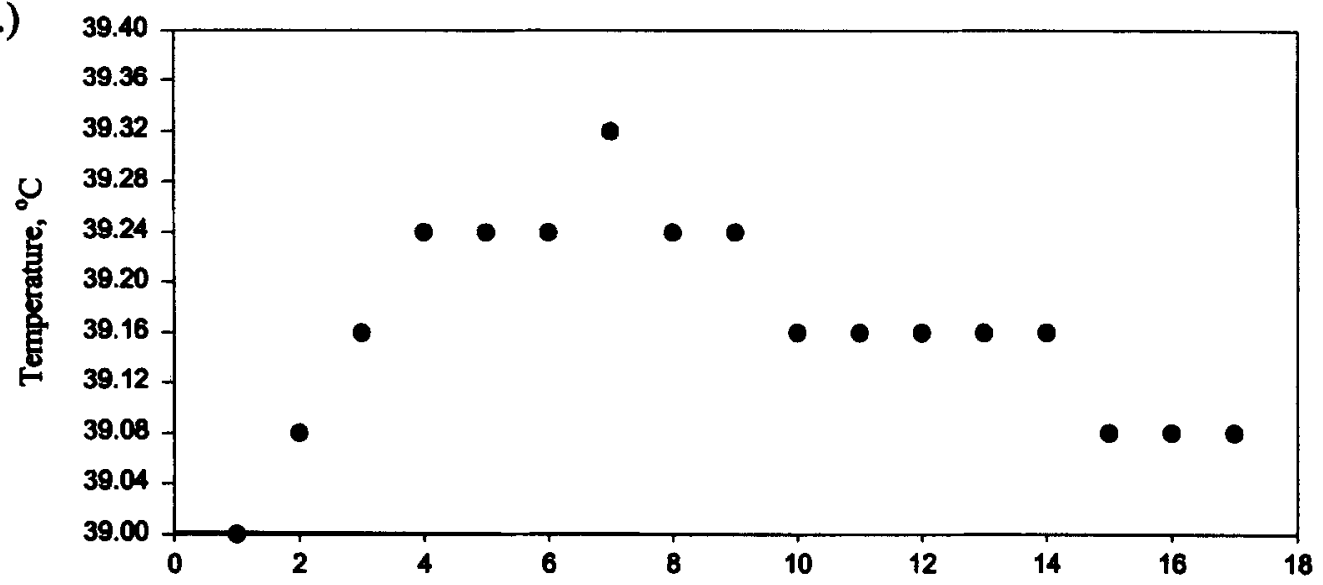

c.)

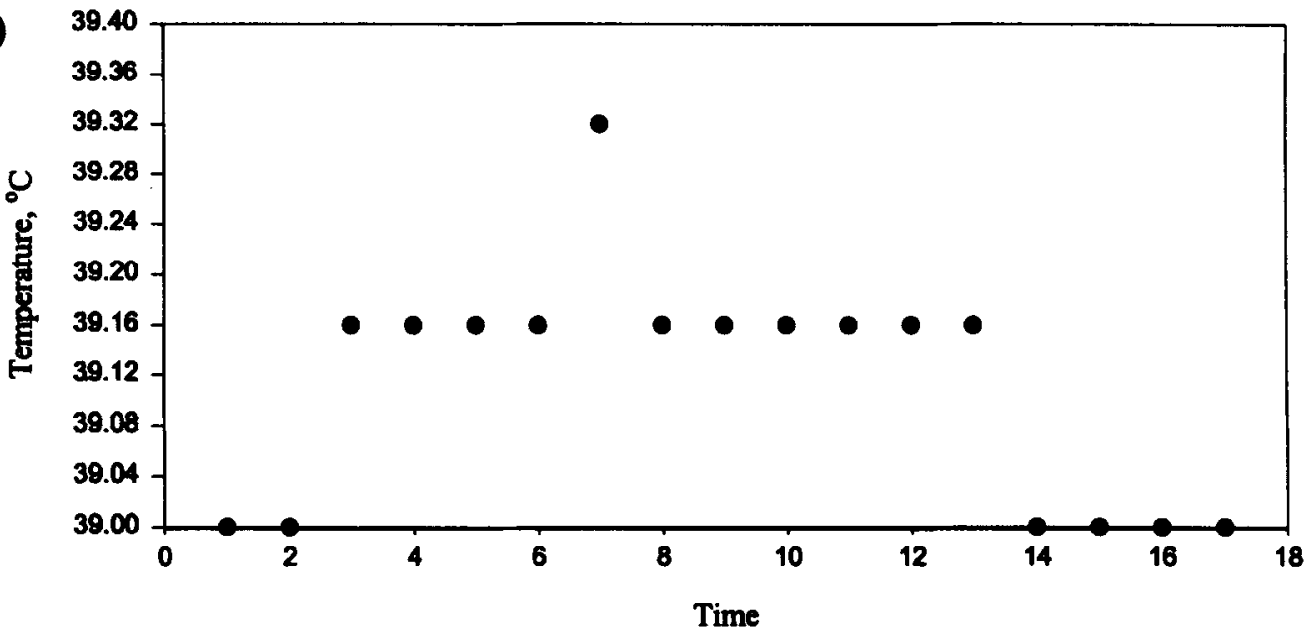

Fig. 2. Representation of how original $0.04^{\circ} \mathrm{C}$ resolution data (a) were modified to derive $0.08^{\circ} \mathrm{C}$ resolution (b) and $0.16^{\circ} \mathrm{C}$ resolutions (c). Data falling between lower resolution levels were replaced by the next lower value of that resolution.

rounded down (Fig. $2 \mathrm{~b}$ ). This procedure was then repeated for datasets with $0.16^{\circ}$ (Fig. $2 \mathrm{c}$ ), $0.32^{\circ}, 0.64^{\circ}$, and $1.28^{\circ} \mathrm{C}$ resolution.
Fractal dimensions of datasets simulating the different resolutions were calculated using every second, fourth, or sixth $(256,512$, and 768 -s intervals) 
data point in the original data files to evaluate the effects of resolution on sampling rate. Comparison of results with those of the original dataset confirmed the hypothesis that improving measurement resolution would not improve the estimation of fractal dimension for a single day's data. Results indicated that a reasonable level of separation of fractal dimensions was maintained for resolutions better than $0.16 \mathrm{C}$ (Fig. 3). With a minimum recommended resolution of $0.16 \mathrm{C}$, separation of fractal dimensions was maintained irrespective of the sampling rate within the range of 256 to $768 \mathrm{~s}$ ( 4.27 to $12.8 \mathrm{~min})$.

\section{Noise}

The effects of normally distributed Gaussian random 'noise' on fractal dimensions were evaluated by adding a Gaussian random number with a standard deviation of $\sigma$ to each point in the third tympanic temperature dataset. The Gaussian random numbers were generated using the function given by Press et al. (1992). Ten different levels of noise $(\sigma)$ were added at multiples of the resolution of the $A / D$ converter $(0.04 \mathrm{C})$ ranging from 0.04 to $0.40 \mathrm{C}$. The original dataset was presumed to be correct (having no noise), and the addition of noise was treated as an additive error occurring on top of the original signal. Changes in fractal dimensions were calculated using a 256-s sampling interval, obtained by removing each second point from the original dataset.

It was expected that the fractal dimension would degrade as noise is added to a dataset until the fractal dimension reflects the noise instead of the true signal. As expected, data with Gaussian noise added had fractal dimensions that exponentially increased towards the limiting value of two, the fractal dimension of a pure Gaussian random signal. An exponential equation was fitted to the set of fractal dimensions computed for data with different levels of noise added $\left(R^{2}=0.88\right)$ of the form:

$$
D^{\prime}=2-(2-D) e^{-k \sigma}
$$

where $D^{\prime}=$ new fractal dimension with noise added, $D=$ original fractal dimension, $k=$ constant $=6.64 \mathrm{C}$, and $\sigma=$ standard deviation of the noise added to the original dataset. With an exponential decay constant of $6.64 \mathrm{C}$, a noise level with a standard deviation of 0.15 (one constant) would compress the range of fractal dimensions to between 1.63 and 2. Similarly, doubling the noise level to a standard deviation of 0.30 would result in fractal dimension ranging from 1.86 to 2 , greatly reducing this method's ability to objectively differentiate stress levels.

\section{Erroneous or missing data}

The effects of erroneous data caused by malfunctioning probes or faulty $\mathrm{A} / \mathrm{D}$ conversions were tested by replacing various numbers of contiguous points with altered points representing selected deviations at an arbitrary, but consistent, starting point in the original data files. Forty-two altered files were created for each original file from the third dataset using every second data point (equivalent to 256-s sampling interval). From these files, consecutive points were subtracted from the first altered tympanic temperature measure, using values of $0.04,0.08,0.16,0.32$, $0.64,1.28$ or $5.12 \mathrm{C}$. As with the Gaussian noise analysis, every second data point was used for

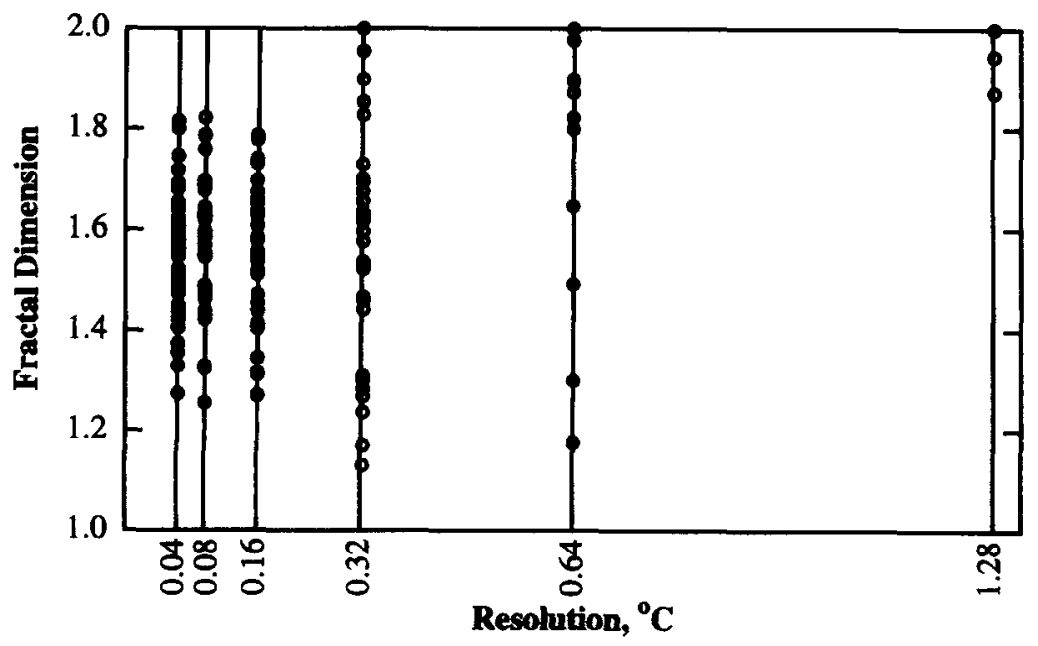

Fig. 3. Effect of resolution on fractal dimension of daily tympanic temperature data in cattle under different levels of heat stress as recorded at intervals of $256 \mathrm{~s}$, near the lowest recommended sampling interval suggested by Hahn et al. (1990b). For resolutions of 0.32 to $1.28^{\circ} \mathrm{C}$, a number of datasets return invalid fractal dimensions, making these levels of resolution unacceptable. 


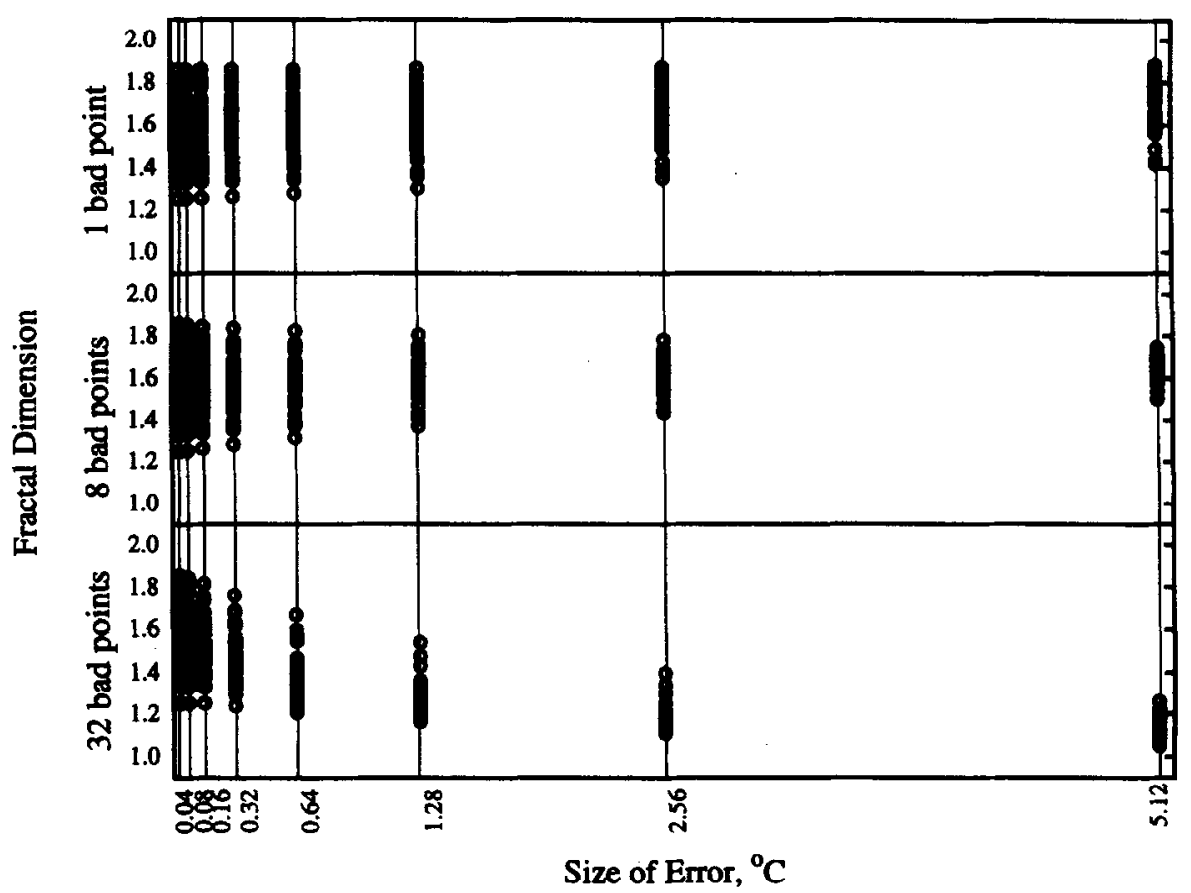

Fig. 4. Fractal dimension of daily tympanic temperature data in cattle sampled at 256-s intervals as affected by consecutive points altered by a fixed size of error.

calculating the fractal dimensions for comparing the effects of erroneous data.

A series of graphs of fractal dimension for different numbers of bad points at different levels of error was made to determine acceptable numbers and sizes of errors (Fig. 4). As more points were replaced with a single value, $\mathrm{D}$ approached 1.0 , reflecting the straight line resulting from the bad points. Based on these graphs, it was further hypothesized that the size of the error could be traded against the number of points in error. Graphing the size of error in fractal dimension against the number of points in error times the size of the error (Fig. 5) indicated that the accuracy of the fractal was indeed a linear relationship. From this

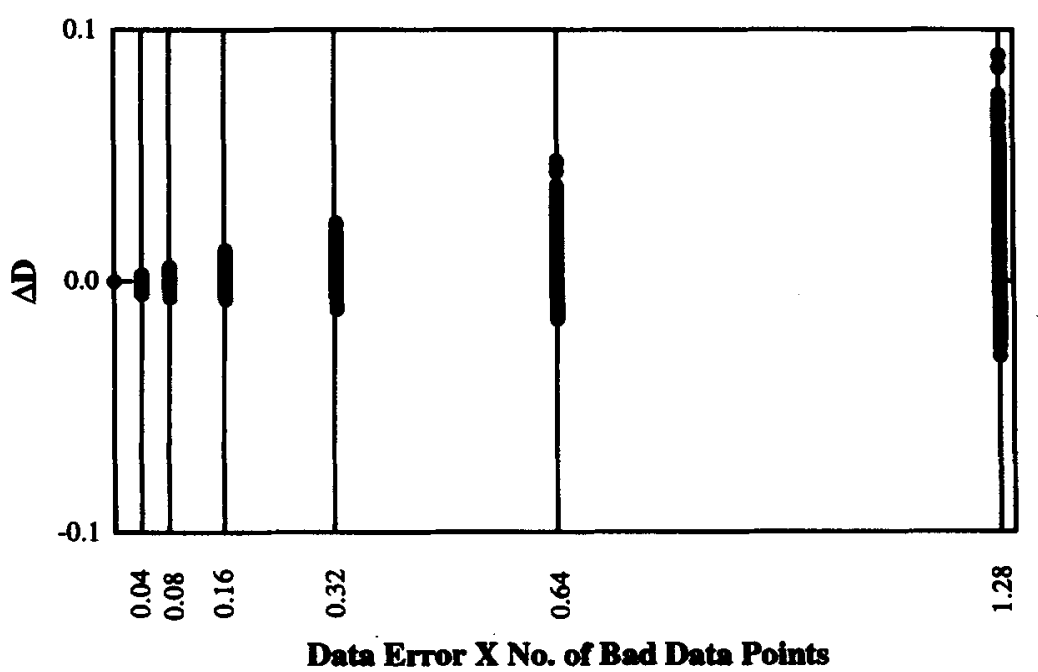

Fig. 5. Change in fractal dimension $(\Delta \mathrm{D})$ calculated with original daily tympanic temperature data in cattle sampled at 256-s intervals versus different levels of introduced errors multiplied by the number of consecutive points with the same level of error (small errors repeated often or occasional large errors produce the same effect). 
relationship, limiting the error in fractal dimension to less than 0.05 requires that the product of the number of erroneous points times the size of their error be less than 0.64 (points $\times$ C). As long as such error limits are noted, substitution of a best guess estimate for a few missing or questionable values can be used when computing fractal dimensions. Examples of good data replacement estimates would include using the last 'good' value, or substituting with a mean or median of nearby surrounding points.

\section{SUMMARY AND IMPLICATIONS}

A procedure is defined for calculating fractal dimensions of tympanic temperatures in animals, and recommendations are given for its use based on analyses of datasets obtained from cattle. A minimum recommended measurement resolution for tympanic temperature is $0.16 \mathrm{C}$. The regular diurnal patterns in cattle tympanic temperature data cause fractal dimensions calculated using 24-h long datasets to vary from results using a portion of that day's data. Accordingly, integer multiples of a full day's data are suggested for calculating fractal dimensions. Tympanic temperature data should be recorded every $180-900 \mathrm{~s}$ ( 3 to $15 \mathrm{~min}$ ), with a sampling interval of one sample every $600-750 \mathrm{~s}$ (10 to $12.5 \mathrm{~min}$ ) being optimal for use in calculating fractal dimensions. Gaussian noise in tympanic temperature data causes the fractal dimension to approach two at an exponential rate of eight times the standard deviation of the noise. For an exponential decay constant of 6.64 , a noise level with a standard deviation of 0.15 (one constant) compresses the range of fractal dimensions to between 1.63 to 2. Doubling the noise level to a standard deviation of 0.30 results in a range of fractal dimension of 1.86 to 2 , making objective differentiation of stress levels with fractal dimensions impossible. Similarly, the number of errors in the data set multiplied by the magnitude of that error linearly decreases the accuracy of the fractal dimension. To limit the impact of such errors on fractal dimension to less than $5 \%$, the number of errors times the magnitude of the errors ( $C$ ) should be limited to less than 0.64 when substituting for missing or questionable data.

The procedures outlined provide a robust methodology for the intended purpose of objectively classifying stress levels from thermoregulatory responses of animals to thermal stressors, even though the prescribed geometric method does not meet all fractal assumptions. Use of the procedures provide fractal values from time series datasets which may contain underlying deterministic functions without the necessity of filtering or otherwise altering the original dataset.

\section{REFERENCES}

Adachi. M. and Kotani, M. (1994) Identification of chaotic dynamical systems withback-propagation neural networks. IEICE Trans, Fundamentals, E77-A, 1, 324. 334.

Baker, M. A., Stocking, R. A. and Meehan, J. P. (1972) Thermal relationships between tympanic temperature and hypothalamus in conscious cat and monkey. $J$. Appl. Physiol. 32, 739.

Benzinger, T. H. (1959) On physical heat regulation and the sense of temperature in man. Proc. Natl. Acad. Sci. USA 45, 645-649.

Benzinger, T. H. (1964) The thermal homeostasis of man. Simp. Soc. Exp. Biol. 18, 49-80.

Carsia, R. V. and Weber. H. (1988) Protein malnutrition in the domestic fowl induces alterations in adrenocortical cell adrenocorticotropin receptors. Endocrinology. 22. 681-688.

Eigenberg. R. A.. Hahn. G. L., Nienaber, J. A.. Parkhurst. A. M. and Kocher. M. F. (1995) Tympanic temperature decay constants as indices of thermal environments: swine. Trans. ASAE. 38, 4, 1203-1206.

Elner, S., Nychka, D. W., and Gallant, A. R. (1992) LENNS, a program to estimate the dominant Lyapunov exponent of noisy nonlinear systems from time series data. Institute of Statistics Mimeo Series \#2235 (BMA Series \#39), Statistics Department, NCSU, Raleigh NC 27695-8203.

Findlay, J. D. and Ingram, D. L. (1961) Brain temperature as a factor in the control of thermal polypnea in the $\mathrm{ox}$ (Bos Taurus). J. Physiol. 155, 72.

Hahn, G. L. (1989) Body temperature rhythms in farm animals-A review and reassessment relative to environmental influences. Proc. $11^{\text {th }}$ Int. Soc. Biometeorology Congr.. SPB Academic Publ. Co., The Hague. 325337.

Hahn, G. L., Parkhurst, A. M, and Nienaber, J. A. (1987) Tympanic temperature rhythms in cattle in selected environments. Tech. Rept. B/A 4.4., Proc. $8^{\text {th }}$ Conf. on Biometeorology/Aerobiology, Amcrican Mctcorological Society, Boston, MA. 320-323.

Hahn, G. L., Eigenberg, R. A., Nienaber, J. A. and Littledike, E. T. (1990a) Measuring physiological responses of animals to environmental stressors using a portable datalogger. J. Animal Sci. 68, 2658-2665.

Hahn. G. L.. Chen, Y. R., Nienaber, J. A. and Eigenberg, R. A. (1990b) Characterizing livestock stress "By the numbers". ASAE paper 904508 , ASAE, St. Joseph, M1 49085-9659.

Hahn, G. L., Chen, Y. R., Nienaber, J. A., Eigenberg. R. A. and Parkhurst, A. M. (1992) Characterizing animal stress through fractal analysis of thermoregulatory responses J. Therm. Biol. 17, 2, 115-120.

Korthals, R. L., Hahn, G. L., Nienaber, J. A., McDonald, T. P. and Eigenberg, R. A. (1992) Experiences with transponders for monitoring bioenergetic responses. ASAE paper 923010 , ASAE, St. Joseph, MI 49085-9659

Korthals, R. L., Eigenberg, R. A., Hahn, G. L. and Nienaber, J. A. (1995) Measurement and spectral analysis of tympanic temperature regulation in swine. Trans. ASAE 38, 3, 905-909. 
Macauley, A. S., Hahn G. L., Clark, D. H. and Sisson, D. V. (1995) Comparison of calf housing types and tympanic temperature rhythms in Holstein calves. J. Dairy Sci. 78, 856-862.

Mandelbrot, B.B. (1983) The Fractal Geometry of Nature. W.H. Freeman and Co., New York.

National Research Council. (1981) Effect of Environment on Nutrient Requirements of Domestic Animals. National Academy Press, Washington, DC.

National Research Council. (1987) Predicting Feed Intake of Food-Producing Animals. National Academy Press, Washington, DC.

Nienaber, J.A. and Hahn, G.L. (1991) Associations among body temperature, eating and heat production in swine and cattle. In: Energy Metabolism in Farm Animals, Ed. C Wenk and M. Boessinger. Proceedings of the $12^{\text {th }}$ Symposium European Assoc. An. Prod., 58, 458-461

Otto-Pietgen, H. and Saupe, D. (1988) The Science of Fractal Images. Springer-Verlag, New York, NY.

Parkhurst, A. M. and Hahn, G. L. (1987) Data dependent systems time series analysis of cattle tympanic temperature rhythms. ASAE paper MCR87-131, ASAE, St Joseph, MI 49085.

Parkhurst, A. M. and Hahn, G. L. (1989) Statistical issues in studies of thermoregulation in farm animals. Proc. Conference on Applied Statistics in Agriculture, pp 21-33. Kansas State Univ., Manhattan KS.
Pentland, A. P. (1984) Fractal-based description of natural scenes. IEEE Trans. on Pattern Analysis and Machine Intelligence. PAMI-6(6), 661-674.

Press, W. H., Teukolsky, S. A., Vetterling, W. T. and Flanner, B. P. (1992) Numerical Recipes in C. Cambridge University Press, 110 Midland Ave., Port Chester, NY 10573. 274-290.

Scott, N. R., Johnson, A. T, and van Tienhoven, A. (1970) Measurement of hypothalamic temperature and heart rate of poultry. Trans. ASAE 13, 342.

Smidt, D. (ed.) (1983) Indicators Relevant to Farm Animal Welfare. M. Nijhoff Publishers, Boston.

Stepp, E.(ed.) (February, 1995) Fractal frequently asked questions and answers. Available URL: http:/ www.cis.ohio-state.edu/hypertext/faq/usenet/fractal-faq/ faq.html.

von Bertalanffy, L. (1968) General Systems Theory (Revised Ed.):44. George Braziller, Inc., New York.

Voss, R. F. (1988) Fractals in nature: from characterization to simulation. Ch. 1 pp. 21-70. In H. O. Peitgen and D. Saupe (eds.), The Science of Fractal Images. SpringerVerlag. New York/Berlin.

West, B. J. and Deering, B. (1995) The lure of modern science: fractal thinking. Studies of Nonlinear Phenomena in Life Sciences, Vol. 3. World Scientific, Singapore. 